\title{
Liver resection versus radiofrequency ablation for hepatitis B virus-related small hepatocellular carcinoma
}

This article was published in the following Dove Press journal: Journal of Hepatocellular Carcinoma

\author{
Bin Liang ${ }^{1,2}$ \\ Siyang $\mathrm{Yao}^{2}$ \\ Jiapeng Zhou ${ }^{3}$ \\ Zongkui $\mathrm{Li}^{1,2}$ \\ Tianqi Liu ${ }^{2}$ \\ 'Department of Graduate School, \\ The Guangxi Medical University, \\ ${ }^{2}$ Department of Hepatobiliary Surgery, \\ The People's Hospital of Guangxi \\ Zhuang Autonomous Region, Nanning, \\ ${ }^{3}$ Department of Hepatobiliary \\ Surgery, The First People's Hospital of \\ Qinzhou, Qinzhou, People's Republic \\ of China
}

Correspondence: Tianqi Liu

Department of Hepatobiliary Surgery,

The People's Hospital of Guangxi Zhuang

Autonomous Region, 6 Taoyuan Road,

Nanning, Guangxi Zhuang Autonomous

Region 53002I, People's Republic of

China

Tel/fax +86 77I 2186550

Email ljrqt@I26.com
Background: To compare the outcomes of liver resection (LR) with radiofrequency ablation (RFA) for patients with hepatitis B virus (HBV)-related small hepatocellular carcinoma (HCC). Methods: A total of $122 \mathrm{HBV}$-related small HCC patients who underwent LR ( $\mathrm{n}=64)$ or RFA $(n=58)$ were involved in this retrospective study. Their basic clinical data, postoperative complications, survival outcomes, and prognostic factors were compared and analyzed.

Results: Patients in the LR group had more serious complications (11 versus 0 ) and longer postoperative hospital stays ( 11.3 versus 6.0 days) than those in the RFA group (all $P<0.05$ ). LR was associated with better recurrence-free survival (RFS) rates at 1, 3, and 5 years compared with RFA $(90.4 \%, 65.9 \%$, and $49.5 \%$ versus $79.3 \%, 50.3 \%$, and $35.6 \%, P=0.037)$, but there was no significant difference in overall survival (OS) $(95.2 \%, 78.1 \%, 58.6 \%$ versus $93.1 \%$, $71.3 \%, 52.9 \%, P=0.309$ ). Multivariate Cox analysis showed that the hepatic cirrhosis (hazard ratio [HR]: 2.13), tumor number (HR: 3.73), tumor diameter (HR: 1.92), and postoperative anti-HBV therapy (HR: 0.53) had predictive values for RFS, and the latter three (HR: 4.34, 2.30 , and 0.44 ) were independent predictors of OS (all $P<0.05$ ).

Conclusion: LR might be considered the preferred method for patients with HBV-related small HCC, while RFA could apply to selective cases. Anti-HBV therapy after treatment was recommended.

Keywords: liver resection, hepatitis B virus, hepatocellular carcinoma, radiofrequency ablation, survival

\section{Background}

Hepatocellular carcinoma (HCC) is one of the most prevalent primary malignancies of the liver and is the leading cause of cancer-related deaths. ${ }^{1}$ The high incidence is partly due to the elevated chronic hepatitis B virus (HBV) prevalence, which is seen in $55 \%-60 \%$ of persons worldwide and in more than $70 \%$ in Asian countries in patients with HCC. ${ }^{2}$ Currently, liver resection (LR) and radiofrequency ablation (RFA) are usually considered as curative treatments of small HCCs, while the donor shortage greatly limits the applicability of liver transplantation. ${ }^{3}$

Over the past decades, although many studies worldwide have investigated the treatment of LR and RFA in patients with small HCCs, the use of these methodologies remains a controversial issue and has not yet been standardized, especially in the East, with its high prevalence of $\mathrm{HBV}$ infection. ${ }^{4}$ In this study, we compared the outcomes and explored the relevant prognostic factors of patients with HBV-related small HCC who underwent LR or RFA as the primary treatment through retrospective 
analysis, aiming to determine the efficacy of different treatment selection.

\section{Methods}

\section{Patients}

This study was approved by the People's Hospital of Guangxi Zhuang Autonomous Region Institutional Review Board and conformed to the ethical guidelines of the Declaration of Helsinki. A total of 578 patients with HCC underwent LR or RFA as the primary treatment from January 2011 to December 2016 in our hospital. Their medical records were retrospectively reviewed. Of these, 122 patients were selected in this study who met the following criteria: 1) the presence of small $\mathrm{HCC}$ ( $\leq 5 \mathrm{~cm}$ or $\leq 3 \mathrm{~cm}$ and no more than 3 lesions); 2) comorbid chronic HBV infection; 3) Child-Pugh class A or B and good performance status; 4) absence of vascular invasion, decompensated liver cirrhosis, and metastatic disease; and 5) follow-up for at least 6 months.

Because of the retrospective nature of the study, patient consent to review their medical records was waived by the approving of the People's Hospital of Guangxi Zhuang Autonomous Region Institutional Review Board. The presented data of participants are anonymized, and the risk of identification is low.

\section{Diagnosis}

The diagnosis of HCC was confirmed by histopathology after resection for patients in the LR group, while percutaneous needle biopsy was performed for all of the patients in the RFA group. Primary treatment was defined before any previous treatment in both groups at the time of diagnosis of HCC. $\mathrm{HBV}$-related HCC was identified in the patients with $\mathrm{HCC}$ who were diagnosed with coexisting presence of serum hepatitis B surface antigen. ${ }^{5}$ Contrast-enhanced ultrasound and/or multiphase contrast-enhanced spiral computed tomography scan with an instrumental criterion was used in the diagnosis of cirrhosis and in the measurement of the tumor number and diameter. Recurrence was defined as the emergence of a new tumor inside or outside the liver, including residual active tumor within or near the previous site found more than 1 month following the first treatment.

\section{Treatments}

The therapeutic benefits and potential risks of LR and RFA were provided to each patient in detail, and the final treatment modality was determined by individual patients after the surgeon's suggestion was given. Informed consent forms were signed by all of the included patients before the treatment of LR or RFA.
Both LR and RFA were performed by the same experienced surgical group. Anatomical liver resection (ALR) was given priority to be applied to the patients while it was possible, and nonanatomical liver resection (NALR) was used in tumors adjacent to the main vasculature, and attempts were made to maintain an adequate surgical margin of at least 1.0 $\mathrm{cm}$. Percutaneous RFA was conducted under sonographic (SSD-3500, Aloka, Chiba, Japan) guidance operated by the same experienced sonographer, and the tumors were completely ablated in automatic impedance control mode with the Radiofrequency System (RF 2000, USA). Percutaneous ethanol injection (PEI) was combined with RFA when the HCC lesions were in high-risk locations, such as near major vasculature, the liver surface, the gallbladder, or the gastrointestinal tract. ${ }^{6}$

\section{Follow-up}

All of the patients selected in the study were followed up with biochemical liver function and serum alpha-fetoprotein (AFP) tests and ultrasonography or computed tomography/ magnetic resonance imaging examinations every 3-6 months until death or the end of the study. Recurrent tumors were managed by individualized therapy plans, which included repeated LR or RFA, transcatheter arterial chemoembolization, and oral sorafenib therapy. The time to tumor recurrence and overall survival (OS) were recorded. Follow-up data were collected until December 31, 2016.

\section{Statistical analysis}

The data of the patients were statistically analyzed using IBM SPSS software, version 22.0 (Armonk, NY, USA) for Windows. Continuous variables were evaluated with a single-factor analysis of variance. Categorical variables were compared using the chi-square test. Recurrence-free survival (RFS) and OS data were analyzed using the Kaplan-Meier method, and all survival curves in the two groups were compared using the log-rank test. Moreover, a Cox regression model was used to identify the prognostic factors. Multivariate analysis was executed for those factors with $P$-values $<0.2$ in univariate analysis. A $P$-value $<0.05$ was considered to indicate a statistically significant difference.

\section{Results}

\section{Patients' characteristics}

In this study, 122 patients who satisfied the inclusion criteria were selected: 64 of these underwent LR and 58 were treated with RFA. In the LR group, 47 patients received ALR, and 17 underwent NALR. In the other group, 37 patients were 
treated with RFA alone, and the remaining 21 had combined therapy with PEI. All of them were diagnosed with HCC by histopathology after treatment. The median follow-up times were 34.9 months (range, 7-66 months) in the LR group and 36.1 months (range, 9-66 months) in the RFA group.

The baseline characteristics of all of the patients in both the LR and RFA groups are shown in Table 1. All the data of sex, age, serum carcinoembryonic antigen (CEA), the positive rate of AFP, total bilirubin (TB), albumin (ALB), alanine aminotransferase (ALT), and aspartate aminotransferase (AST), platelet count (PLT), the hepatitis B virus DNA levels (HNB-DNA), Child-Pugh classification, the presence of cirrhosis, the tumor number, and the maximum tumor diameter in both groups showed no significant differences between the two groups (all $P>0.05$ ). In addition, the number of patients who received anti-HBV therapy after surgery was

Table I Baseline characteristics of 122 patients treated with LR or RFA

\begin{tabular}{|c|c|c|c|}
\hline Characteristics & $\begin{array}{l}\text { LR group } \\
(n=64)\end{array}$ & $\begin{array}{l}\text { RFA group } \\
(n=58)\end{array}$ & $P$-value \\
\hline Sex & & & 0.810 \\
\hline Male & 54 (84.3\%) & 48 (82.8\%) & \\
\hline Female & $10(15.6 \%)$ & $10(17.2 \%)$ & \\
\hline Age (years) & $48.8(26-74)$ & $51.4(30-85)$ & 0.218 \\
\hline \multicolumn{4}{|l|}{ Serum biochemistry } \\
\hline CEA $(\mu g / L)$ & $1.3(0.5-4.6)$ & $1.6(0.5-4.3)$ & 0.087 \\
\hline $\operatorname{AFP}(>400 \mathrm{ng} / \mathrm{mL})$ & 18 (28.1\%) & $9(15.5 \%)$ & 0.094 \\
\hline $\mathrm{TB}(\mathrm{mg} / \mathrm{dL})$ & $13.2(3.4-36.4)$ & $\mid 4.2(4.4-3 \mid .0)$ & 0.333 \\
\hline ALB (g/dL) & $38.6(30.0-45.2)$ & $37.8(28.7-44.4)$ & 0.180 \\
\hline ALT (U/L) & $49.2(9-151)$ & $33.5(13-104)$ & 0.132 \\
\hline AST (U/L) & $34.9(16-134)$ & $35.1(|4-7|)$ & 0.971 \\
\hline PLT $\left(\times 10^{3} / \mathrm{L}\right)$ & $187.8(68-4 \mid 7)$ & 177.7 (74-274) & 0.385 \\
\hline $\begin{array}{l}\text { HBV DNA levels } \\
(>500 \mathrm{U} / \mathrm{mL})\end{array}$ & $42(65.6 \%)$ & 32 (55.2\%) & 0.238 \\
\hline Child-Pugh & & & 0.884 \\
\hline \multicolumn{4}{|l|}{ classification } \\
\hline$A$ & 58 (90.6\%) & 53 (91.4\%) & \\
\hline B & $6(9.4 \%)$ & $5(8.6 \%)$ & \\
\hline Hepatic cirrhosis & & & 0.729 \\
\hline Absent & 24 (37.5\%) & 20 (34.5\%) & \\
\hline Present & 40 (62.5\%) & $38(65.5 \%)$ & \\
\hline Number of tumors & & & 0.251 \\
\hline 1 & 47 (73.4\%) & 37 (63.8\%) & \\
\hline 2 or 3 & $17(26.6 \%)$ & 21 (36.2\%) & \\
\hline $\begin{array}{l}\text { Maximum tumor } \\
\text { diameter }(\mathrm{cm})\end{array}$ & $3.1(1.5-5.0)$ & $2.9(1.2-5.0)$ & 0.070 \\
\hline $\begin{array}{l}\text { Postoperative anti- } \\
\text { HBV therapy }\end{array}$ & $34(53.1 \%)$ & 37 (63.8\%) & 0.233 \\
\hline $\begin{array}{l}\text { Follow-up times } \\
\text { (months) }\end{array}$ & $34.9(7-66)$ & $36.1(9-66)$ & 0.661 \\
\hline
\end{tabular}

Abbreviations: LR, liver resection; RFA, radiofrequency ablation; CEA, carcinoembryonic antigen; AFP, alpha-fetoprotein; TB, total bilirubin; ALB, albumin; ALT, alanine aminotransferase; AST, aspartate aminotransferase; PLT, platelet count; HBV, hepatitis B virus.
$34(53.1 \%)$ in the LR group and 37 (63.8\%) in the RFA group $(P=0.233)$, respectively.

\section{Postoperative characteristics}

Postoperative characteristics are presented in Table 2. Patients in the LR group tended to have lower ALB and higher ALT and AST than those in the RFA group (all $P<0.001$ ), and they were also more vulnerable to having procedure-related complications ( 11 versus $0, P=0.001$ ), including hydrothorax ( 1 case), ascites ( 2 cases), elevated serum pancreatic $\alpha$-amylase ( 6 cases), bleeding ( 1 case), and subphrenic infection ( 1 case). Furthermore, patients who received resection experienced longer postoperative hospital stays than those who underwent ablation; the median postoperative hospital days were 11.3 days (range, 7-25 days) in the LR group and 6.0 days in the RFA group (range, $3-10$ days) $(P<0.001)$. However, postoperative TB, 7-days AFP $>400 \mathrm{ng} / \mathrm{mL}$, and temperature $\geq 38.5^{\circ} \mathrm{C}$ were not significantly different between the two groups. There were no perioperative deaths in either group.

\section{Recurrence and survival}

At the time of censoring, recurrence was observed in 23 of 64 (35.9\%) patients in the LR group and 32 of $58(55.2 \%)$ in the

Table 2 Postoperative characteristics of 122 patients treated with LR or RFA

\begin{tabular}{|c|c|c|c|}
\hline Characteristics & $\begin{array}{l}\text { LR group } \\
(n=64)\end{array}$ & $\begin{array}{l}\text { RFA group } \\
(n=58)\end{array}$ & $P$-value \\
\hline \multicolumn{4}{|l|}{ Postoperative serum } \\
\hline \multicolumn{4}{|l|}{ biochemistry } \\
\hline TB (mg/dL) & $23.0(5.0-59.4)$ & $23.5(8.3-52.7)$ & 0.817 \\
\hline ALB $(g / d L)$ & $31.7(23.0-42.7)$ & $34.8(23.0-44.8)$ & $<0.001$ \\
\hline ALT (U/L) & $315.8(30-926)$ & 135.2 (39-369) & $<0.001$ \\
\hline AST (U/L) & $286.7(40-880)$ & $\mid 78.2(5|-42|)$ & $<0.001$ \\
\hline $\begin{array}{l}\text { 7-days AFP } \\
(>400 \mathrm{ng} / \mathrm{mL})\end{array}$ & $12(18.8 \%)$ & $8(13.8 \%)$ & 0.460 \\
\hline $\begin{array}{l}\text { Postoperative febrile } \\
\left(\geq 38.5^{\circ} \mathrm{C}\right)\end{array}$ & 25 (39.0\%) & $18(31.0 \%)$ & 0.354 \\
\hline $\begin{array}{l}\text { Serious complications } \\
\text { (total) }\end{array}$ & II (I7.2\%) & 0 & 0.001 \\
\hline Hydrothorax & 1 & 0 & \\
\hline Ascites & 2 & 0 & \\
\hline $\begin{array}{l}\text { Serum pancreatic } \\
\alpha \text {-amylase elevated }\end{array}$ & 6 & 0 & \\
\hline Postoperative bleeding & 1 & 0 & \\
\hline Subphrenic infection & I & 0 & \\
\hline Hospital mortality & & & NA \\
\hline $\begin{array}{l}\text { Postoperative hospital } \\
\text { days }\end{array}$ & II.3 (7-25) & $6.0(3-10)$ & $<0.001$ \\
\hline Recurrent cases & $23(35.9 \%)$ & 32 (55.2\%) & 0.033 \\
\hline Death cases & 14 (21.9\%) & $19(32.8 \%)$ & 0.177 \\
\hline
\end{tabular}

Abbreviations: $L R$, liver resection; RFA, radiofrequency ablation; $T B$, total bilirubin; ALB, albumin; ALT, alanine aminotransferase; AST, aspartate aminotransferase; AFP, alpha-fetoprotein; NA, not available. 
RFA group ( $P=0.033)$. The cumulative RFS rates at 1,3 , and 5 years were estimated to be $90.4 \%, 65.9 \%$, and $49.5 \%$ in the LR group and $79.3 \%, 50.3 \%$, and $35.6 \%$ in the RFA group, respectively (Figure1A). The RFS rates were significantly higher in the LR group ( $P=0.037)$. There were 14 (21.9\%) patients who died in the LR group and $19(32.8 \%)$ in the RFA group $(P=0.177)$. The 1-, 3-, 5-year cumulative OS rates in the LR group were $95.2 \%, 78.1 \%$, and $58.6 \%$ and those in the RFA group were $93.1 \%, 71.3 \%$, and $52.9 \%$, respectively (Figure1B). There were no significant differences between the two groups in OS $(P=0.309)$.

\section{Prognostic factors for outcomes}

In univariate analysis of RFS, the $P$-values for CEA, AST, PLT, hepatic cirrhosis, number of tumors, maximum tumor diameter, and postoperative anti-HBV therapy were all $<0.20$. The multivariate analysis of these seven variables showed that hepatic cirrhosis (hazard ratio [HR]: $2.13,95 \% \mathrm{CI}: 1.13-2.76$, $P=0.019$ ), number of tumors (HR: $3.73,95 \% \mathrm{CI}: 1.93-7.20$, $P<0.001$ ), maximum tumor diameter (HR: 1.92, 95\% CI: 1.34-2.76, $P<0.001)$, and postoperative anti-HBV therapy (HR: 0.49 , 95\% CI: $0.30-0.91, P=0.022$ ) were independent prognostic factors associated with RFS.

For OS, univariate analysis showed that the $P$-values of AST, number of tumors, maximum tumor diameter, and postoperative anti-HBV therapy were all $<0.20$. However, by

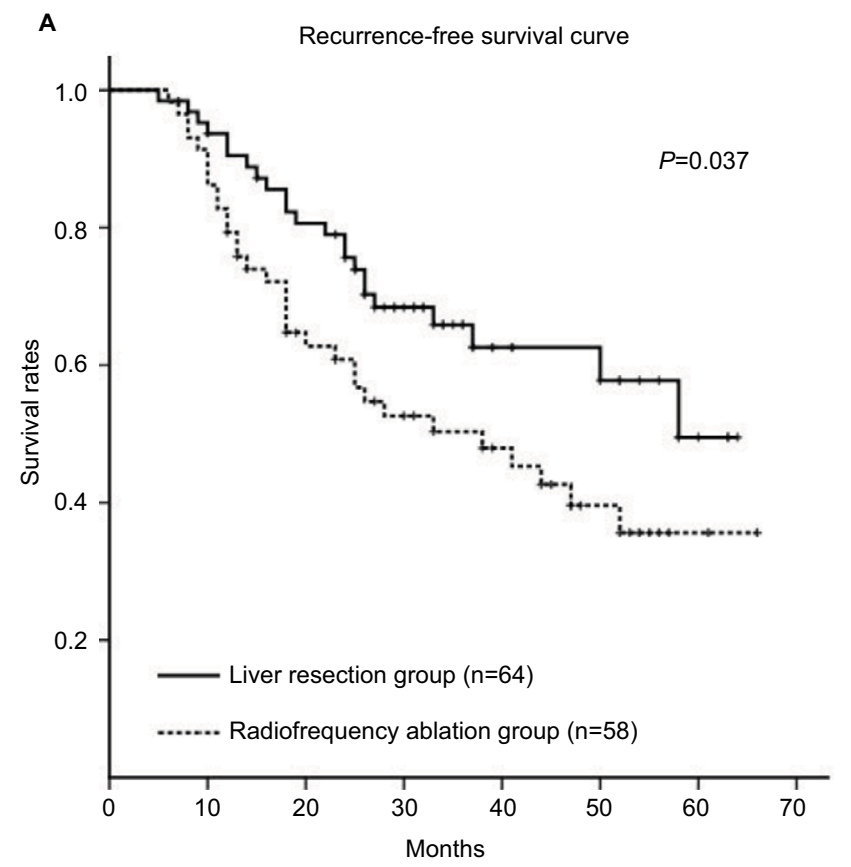

multivariate analysis, the number of tumors (HR: 4.34, 95\% CI: 1.98-9.52, $P<0.001)$, maximum tumor diameter (HR: 2.30, 95\% CI: $1.44-3.69, P=0.001)$, and postoperative antiHBV therapy (HR: $0.44,95 \%$ CI: $0.22-0.89, P=0.023$ ) were significant, independent predictors of OS. Further details are presented in Tables 3 and 4.

\section{Discussion}

$\mathrm{HBV}$ infection is one of the most prevalent risk factors in the development of HCC worldwide, and a large body of research has confirmed the association between viral infection and the occurrence of HCC. ${ }^{7,8}$ Although routine $\mathrm{HCC}$ surveillance of HBV-infected subjects could improve their survival, it has been reported that HBV-related HCC patients have significantly poorer outcomes after treatment than those without $\mathrm{HBV}$ infection. ${ }^{9,10}$ In past decades, numerous studies have compared the outcomes of patients with HCC who underwent LR or RFA; however, there has not been a consistent opinion on which treatment method is superior. Some researchers have confirmed that patients who receive LR have a significantly higher survival rate than those who receive RFA, ${ }^{11-15}$ while some investigations have indicated similar long-term outcomes between the two treatments, ${ }^{16-19}$ and have even reported that RFA was associated with better treatment efficacy than LR in patients with small HCC. ${ }^{20}$ Currently, among HBV-related small HCC cases, there are no

B

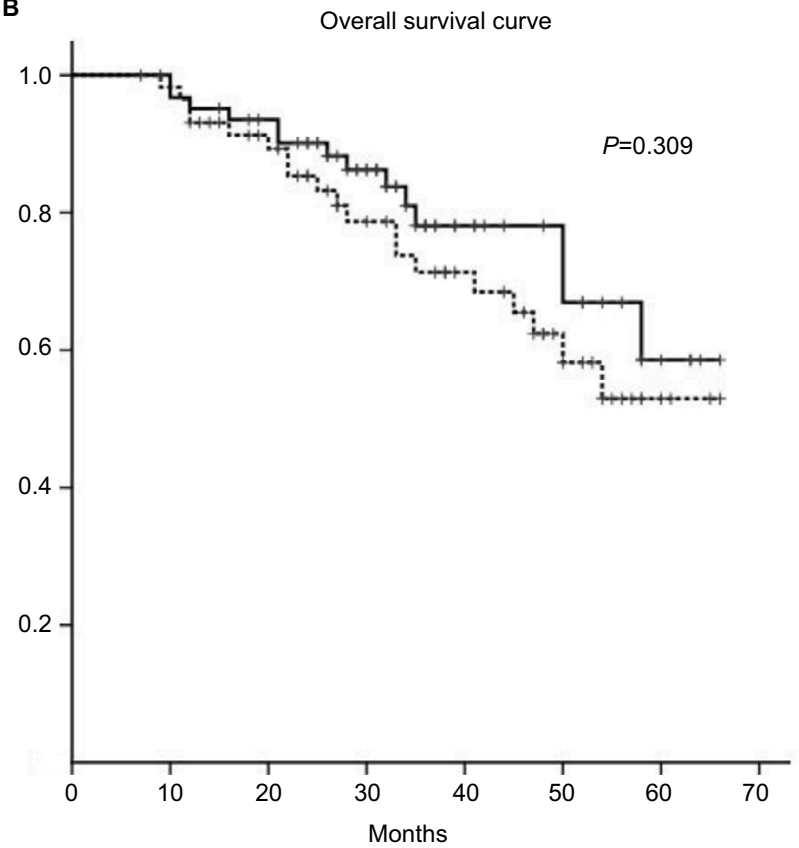

Figure I RFS and OS curves for 122 patients treated with LR or RFA.

Notes: (A) Patients who undergo LR have better RFS rates than those who undergo RFA ( $P=0.037)$; (B) There is no significant difference between two groups in OS rates $(P=0.309)$.

Abbreviations: LR, liver resection; OS, overall survival; RFS, recurrence-free survival; RFA, radiofrequency ablation. 
Table 3 Univariate and multivariate analysis of RFS in patients with HBV-related small HCC

\begin{tabular}{|c|c|c|c|c|}
\hline \multirow[t]{2}{*}{ Variables } & \multicolumn{2}{|c|}{ Univariate analysis } & \multicolumn{2}{|c|}{ Multivariate analysis } \\
\hline & HR (95\% Cl) & $P$-value & HR (95\% Cl) & $P$-value \\
\hline Age (per I year) & 1.01 (0.98-1.03) & 0.694 & & \\
\hline CEA $(\mu \mathrm{g} / \mathrm{L})$ & $1.21(0.91-1.62)$ & 0.193 & $1.05(0.80-1.38)$ & 0.734 \\
\hline $\operatorname{AFP}(>400 \mathrm{ng} / \mathrm{mL})$ & $1.01(0.53-1.91)$ & 0.982 & & \\
\hline $\mathrm{TB}(\mathrm{mg} / \mathrm{dL})$ & $0.99(0.95-1.04)$ & 0.749 & & \\
\hline ALB $(g / d L)$ & $1.01(0.93-1.09)$ & 0.876 & & \\
\hline ALT (U/L) & $1.00(0.98-1.01)$ & 0.755 & & \\
\hline AST (U/L) & $1.01(1.00-1.03)$ & 0.068 & I.0I (0.99-I.02) & 0.409 \\
\hline PLT $\left(<100 \times 10^{3} / L\right)$ & $1.00(0.99-1.00)$ & 0.110 & $1.00(0.99-1.00)$ & 0.413 \\
\hline HBV DNA levels (>500 U/mL) & $0.97(0.56-1.66)$ & 0.907 & & \\
\hline Child-Pugh classification (A/B) & $1.23(0.53-2.87)$ & 0.636 & & \\
\hline Hepatic cirrhosis (Yes/No) & $1.97(1.07-3.61)$ & 0.029 & $2.13(1.13-2.76)$ & 0.019 \\
\hline Number of tumors $(1 / 2$ or 3$)$ & $2.72(1.58-4.66)$ & $<0.001$ & $3.73(1.93-7.20)$ & $<0.00$ । \\
\hline Maximum tumor diameter $(\mathrm{cm})$ & $1.49(1.11-1.99)$ & 0.007 & $1.92(1.34-2.76)$ & $<0.00$ । \\
\hline Postoperative anti-HBV therapy (Yes/No) & $0.49(0.29-0.84)$ & 0.010 & $0.53(0.30-0.91)$ & 0.022 \\
\hline
\end{tabular}

Abbreviations: RFS, recurrence-free survival; HBV, hepatitis B virus; HCC, hepatocellular carcinoma; HR, hazard ratio; Cl, confidence interval; CEA, carcinoembryonic antigen; AFP, alpha-fetoprotein; TB, total bilirubin; ALB, albumin; ALT, alanine aminotransferase; AST, aspartate aminotransferase; PLT, platelet count; HBV, hepatitis B virus.

Table 4 Univariate and multivariate analysis of OS in patients with HBV-related small HCC

\begin{tabular}{|c|c|c|c|c|}
\hline \multirow[t]{2}{*}{ Variables } & \multicolumn{2}{|c|}{ Univariate analysis } & \multicolumn{2}{|c|}{ Multivariate analysis } \\
\hline & HR (95\% Cl) & $P$-value & HR (95\% Cl) & $P$-value \\
\hline Age (per I year) & $1.01(0.98-1.04)$ & 0.637 & & \\
\hline CEA $(\mu g / L)$ & $1.23(0.83-1.82)$ & 0.308 & & \\
\hline $\operatorname{AFP}(>400 \mathrm{ng} / \mathrm{mL})$ & $0.82(0.34-1.98)$ & 0.651 & & \\
\hline TB (mg/dL) & $1.01(0.95-1.07)$ & 0.749 & & \\
\hline ALB (g/dL) & $0.94(0.84-1.04)$ & 0.222 & & \\
\hline $\operatorname{ALT}(\mathrm{U} / \mathrm{L})$ & $1.00(0.98-1.02)$ & 0.804 & & \\
\hline AST (U/L) & $1.02(1.00-1.03)$ & 0.067 & $1.01(0.99-1.03)$ & 0.129 \\
\hline PLT $(<100 \times 103 / L)$ & $1.00(0.99-1.00)$ & 0.289 & & \\
\hline HBV DNA levels $(>500 \mathrm{U} / \mathrm{mL})$ & $1.23(0.60-2.50)$ & 0.574 & & \\
\hline Child-Pugh classification (A/B) & $1.54(0.54-4.38)$ & 0.423 & & \\
\hline Hepatic cirrhosis (Yes/No) & $1.06(0.52-2.16)$ & 0.869 & & \\
\hline Number of tumors ( $1 / 2$ or 3$)$ & $2.90(I .45-5.8 I)$ & 0.003 & $4.34(1.98-9.52)$ & $<0.001$ \\
\hline Maximum tumor diameter $(\mathrm{cm})$ & $1.71(1.17-2.49)$ & 0.006 & $2.30(1.44-3.69)$ & 0.001 \\
\hline Postoperative anti-HBV therapy & $0.44(0.22-0.88)$ & 0.021 & $0.44(0.22-0.89)$ & 0.023 \\
\hline
\end{tabular}

Abbreviations: OS, overall survival; $\mathrm{HBV}$, hepatitis B virus; $\mathrm{HCC}$, hepatocellular carcinoma; $\mathrm{HR}$, hazard ratio; Cl, confidence interval; CEA, carcinoembryonic antigen; AFP, alpha-fetoprotein; TB, total bilirubin; ALB, albumin; ALT, alanine aminotransferase; AST, aspartate aminotransferase; PLT, platelet count; HBV, hepatitis B virus.

data comparing the clinical outcomes of LR with RFA, and our study was performed to explore the difference between these two treatments in such a cohort.

Recently, several studies have reported that LR was associated with a lower recurrence risk but similar OS, compared with RFA in early-stage HCC patients..$^{14,21,22}$ Consistent with this finding, our study also found the same outcomes between LR and RFA in HBV-related small HCC. Patients in the LR group achieved better cumulative RFS rates at 1 , 3 , and 5 years than those in the RFA group $(P=0.037)$ but comparable OS rates between the two groups $(P=0.309)$. LR has the advantage of removing the tumor-adjacent territory, likely including minute satellite lesions, especially in patients who underwent anatomical resection, which could offer better local control of HCC than RFA. ${ }^{23}$ In the present study, recurrence was observed in 55.2\% (32/50) of cases in the RFA group, which was significantly higher than in the LR group with $35.9 \%$ (23/64) relapse during the follow-up period $(P=0.033)$. According to previous reports, the recurrence rate in HBV-related HCC patients who underwent RFA treatment was $52.4 \%-60.8 \%$ after a 5 -year follow-up, and the risk of recurrence was increased with the lower PLT, higher HBV DNA levels, and the tumor topographical factors (including the number, larger size, and proximity to major vessels or the diaphragm). ${ }^{24-28}$

Despite a significantly lower RFS in the RFA group, the OS was comparable in both groups. Such outcomes could probably be attributed to regular visits after surgery, which 
could detect early recurrence and ensure that patients received timely retreatment with individual methods. ${ }^{21}$ Additionally, our study showed that patients who underwent RFA experienced fewer treatment-related complications and shorter postoperative hospital stays. These results were consistent with previous studies. ${ }^{11-14,16}$ Accompanied by the advantage of liver functional reserve, offering better tolerability, good repeatability, and cost-effectiveness, ${ }^{29}$ RFA could be considered an alternative therapy for selected patients with small HCC, such as those with worse liver function and older candidates.

In these patients, the results of multivariate analysis in our study showed that the presence of hepatic cirrhosis, multiple tumors, and larger tumor diameter were significant independent risk predictors of RFS, while only multiple tumors and larger tumor diameter were risk factors associated with OS. Similarly, a previous study demonstrated that intervention (resection versus ablation), tumor number, tumor diameter, and a high level of serum AFP were independent risk factors for RFS and OS for early-stage HCC. ${ }^{13}$ This finding suggests that HBV-related HCC patients with hepatic cirrhosis, multiple tumors, and larger tumor diameters should undergo enhance surveillance after treatment, especially those who undergo RFA.

Our study showed that postoperative anti-HBV therapy was an independent protective factor for both RFS and OS. This result was in agreement with several previous studies. ${ }^{30-33}$ A randomized controlled trial demonstrated that anti-HBV therapy after treatment significantly reduced recurrence and improved OS in patients with $\mathrm{HBV}$-related HCC. ${ }^{30}$ Urata et $\mathrm{al}^{31}$ suggested that a high serum level of HBV DNA was a notable risk factor for recurrence after surgery for HBV-related HCC, and antiviral therapy could improve the long-term outcomes. Ke et $\mathrm{al}^{32}$ indicated that postoperative anti-HBV therapy could significantly prolong survival time by increasing the likelihood of the patient receiving curative treatments in the event of a relapse and that it prevented death due to liver failure, especially in patients with early- or median-stage HCC. Hence, anti-HBV therapy after LR or RFA can be highly recommended in patients with HBVrelated small HCC to attain the benefit of better outcomes.

There were several limitations in our study. First, because of the retrospective study design, there was potential for selection bias, as well as with the presence of uncontrolled confounding factors between the two groups. Second, there is no comparison of recurrence patterns and treatment modalities for recurrent tumor which may influence the results in this study. However, we plan to further our study by increasing the sample size and comparing the recurrence to confirm the outcomes of these cohorts after treatment.

\section{Conclusion}

For patients with HBV-related small HCC, LR provided better RFS than RFA but had a similar OS in comparison. Patients who underwent RFA had fewer complications and shorter postoperative hospital stays. LR might be considered the preferred method for these patients, while RFA could apply to selective patients who would be unable to tolerate surgical resection. Hepatic cirrhosis, tumor number, and maximum tumor diameter were independent prognostic factors of longterm outcomes in this cohort, and anti-HBV therapy after treatment was recommended.

\section{Acknowledgments}

This study was supported by grants from the Project of Guangxi Scientific Research and Technology Development plan, China (2013BC26214). The authors thank Dr Xixia Liu and Dr Xiaofeng Dong, who have been a source of encouragement and inspiration.

\section{Disclosure}

The authors report no conflicts of interest in this work.

\section{References}

1. Torre LA, Bray F, Siegel RL, Ferlay J, Lortet-Tieulent J, Jemal A. Global cancer statistics, 2012. CA Cancer J Clin. 2015;65:87.

2. Chau GY. Resection of hepatitis B virus-related hepatocellular carcinoma: evolving strategies and emerging therapies to improve outcome. World J Gastroenterol. 2014;20:12473-12484.

3. Daoudaki M, Fouzas I. Hepatocellular carcinoma. Wien Med Wochenschr. 2014;164:450-455.

4. Chu KK, Cheung TT. Update in management of hepatocellular carcinoma in Eastern population. World J Hepatol. 2015;7:1562-1571.

5. Cheng S, Zhang B, Du JY, Jin YH, Lang HY, Zeng LH. Hepatitis B surface antigen promotes the invasion of hepatitis B virus-related hepatocellular carcinoma cells by upregulation of toll-like receptor 2 . Viral Immunol. 2017;30:232-239.

6. Cha DI, Lee MW, Rhim H, Choi D, Kim YS, Lim HK. Therapeutic efficacy and safety of percutaneous ethanol injection with or without combined radiofrequency ablation for hepatocellular carcinomas in high risk locations. Korean J Radiol. 2013;14:240-247.

7. Dhanasekaran R, Limaye A, Cabrera R. Hepatocellular carcinoma: current trends in worldwide epidemiology, risk factors, diagnosis, and therapeutics. Hepat Med. 2012;4:19-37.

8. Tanaka M, Katayama F, Kato H, et al. Hepatitis B and C virus infection and hepatocellular carcinoma in China: a review of epidemiology and control measures. J Epidemiol. 2011;21:401-416.

9. Tong MJ, Siripongsakun S, Stanford-Moore G, Hsu L, Chang PW, Blatt LM. Tumor factors associated with clinical outcomes in patients with hepatitis B virus infection and hepatocellular carcinoma. Gastroenterol Hepatol (N Y). 2012;8:808-819.

10. Utsunomiya T, Shimada M, Kudo M, et al. A comparison of the surgical outcomes among patients with HBV-positive, HCV-positive, and non-B non-C hepatocellular carcinoma: a nationwide study of 11,950 patients. Ann Surg. 2014;261:513-520. 
11. Gory I, Fink M, Bell S, et al. Radiofrequency ablation versus resection for the treatment of early stage hepatocellular carcinoma: a multicenter Australian study. Scand J Gastroenterol. 2015;50:567-576.

12. Liu PH, Hsu CY, Hsia CY, et al. Surgical resection versus radiofrequency ablation for single hepatocellular carcinoma $\leq 2 \mathrm{~cm}$ in a propensity score model. Ann Surg. 2016;263:538-545.

13. Guan TP, Fang CH, Yang J, Xiang N, Chen QS, Zhong SZ. A comparison between three-dimensional visualization guided hepatectomy and ultrasonography guided radiofrequency ablation in the treatment of small hepatocellular carcinoma within the Milan criteria. Biomed Res Int. 2016;2016:1-10.

14. Li J, Yan L, Wen T, et al. Comparison of outcomes of hepatic resection and radiofrequency ablation for hepatocellular carcinoma patients with multifocal tumors meeting the Barcelona-clinic liver cancer stage a classification. J Am Coll Surg. 2015;221:951.

15. Parisi A, Desiderio J, Trastulli S, et al. Liver resection versus radiofrequency ablation in the treatment of cirrhotic patients with hepatocellular carcinoma. Hepatobiliary Pancreat Dis Int. 2013;12(3):270-277.

16. Kang TW, Kim JM, Rhim H, et al. Small hepatocellular carcinoma: radiofrequency ablation versus nonanatomic resection-propensity score analyses of long-term outcomes. Radiology. 2015;275:908-919.

17. Fang Y, Chen W, Liang X, et al. Comparison of long-term effectiveness and complications of radiofrequency ablation with hepatectomy for small hepatocellular carcinoma. J Gastroenterol Hepatol. 2014;29:193.

18. Tohme S, Geller DA, Cardinal JS, et al. Radiofrequency ablation compared to resection in early-stage hepatocellular carcinoma. $H P B$ (Oxford). 2013;15:210-217.

19. Pompili M, Saviano A, Matthaeis ND, et al. Long-term effectiveness of resection and radiofrequency ablation for single hepatocellular carcinoma $\leq 3 \mathrm{~cm}$. Results of a multicenter Italian survey. J Hepatol. 2013;59:89-97.

20. Lee YH, Hsu CY, Chu CW, et al. Radiofrequency ablation is better than surgical resection in patients with hepatocellular carcinoma within the Milan criteria and preserved liver function: a retrospective study using propensity score analyses. J Clin Gastroenterol. 2015;49:242-249.

21. Harada N, Shirabe K, Maeda T, Kayashima H, Takaki S, Maehara Y. Comparison of the outcomes of patients with hepatocellular carcinoma and portal hypertension after liver resection versus radiofrequency ablation. World J Surg. 2016;40:1709-1719.
22. Liu PH, Hsu CY, Lee YH, et al. When to perform surgical resection or radiofrequency ablation for early hepatocellular carcinoma?: a nomogram-guided treatment strategy. Medicine (Baltimore). 2015;94:e1808.

23. Shindoh J, Makuuchi M, Matsuyama Y, et al. Complete removal of the tumor-bearing portal territory decreases local tumor recurrence and improves disease-specific survival of patients with hepatocellular carcinoma. J Hepatol. 2016;64:594-600.

24. Li F. Recurrence of hepatitis B virus-related hepatocellular carcinoma after radiofrequency ablation: a multivariate analysis. Chinese Rem Clin. 2015;12:1705-1708.

25. Sohn W, Paik YH, Lee MW, et al. Predisposing factors for recurrence of HBV-related small hepatocellular carcinoma after percutaneous radiofrequency ablation. Scand J Gastroenterol. 2014;49:373-380.

26. Goto T, Yoshida H, Tateishi R, et al. Influence of serum HBV DNA load on recurrence of hepatocellular carcinoma after treatment with percutaneous radiofrequency ablation. Hepatol Int. 2011;5:767-773.

27. Kim JS, Kim W, So YH, Yu SJ, Kim BG. Topographical impact of hepatitis B-related hepatocellular carcinoma on local recurrence after radiofrequency ablation. J Clin Gastroenterol. 2014;48:66-72.

28. Kim YS, Lim HK, Rhim H, et al. Ten-year outcomes of percutaneous radiofrequency ablation as first-line therapy of early hepatocellular carcinoma: analysis of prognostic factors. J Hepatol. 2013;58: 89-97.

29. Cucchetti A, Piscaglia F, Cescon M, et al. Cost-effectiveness of hepatic resection versus percutaneous radiofrequency ablation for early hepatocellular carcinoma. J Hepatol. 2013;59:300.

30. Huang G, Lau WY, Wang ZG, et al. Antiviral therapy improves postoperative survival in patients with hepatocellular carcinoma: a randomized controlled trial. Ann Surg. 2015;261:56.

31. Urata Y, Kubo S, Takemura S, et al. Effects of antiviral therapy on longterm outcome after liver resection for hepatitis B virus-related hepatocellular carcinoma. J Hepatobiliary Pancreat Sci. 2012;19:685-696.

32. Ke Y, Ma L, You XM, et al. Antiviral therapy for hepatitis B virus-related hepatocellular carcinoma after radical hepatectomy. Cancer Biol Med. 2013;10:158-164.

33. Ishikawa T. Anti-viral therapy to reduce recurrence and improve survival in hepatitis B virus-related hepatocellular carcinoma. World J Gastroenterol. 2013;19(47):8861-8866.
Journal of Hepatocellular Carcinoma

\section{Publish your work in this journal}

The Journal of Hepatocellular Carcinoma is an international, peerreviewed, open access journal that offers a platform for the dissemination and study of clinical, translational and basic research findings in this rapidly developing field. Development in areas including, but not limited to, epidemiology, vaccination, hepatitis therapy, pathology and

\section{Dovepress}

molecular tumor classification and prognostication are all considered for publication. The manuscript management system is completely online and includes a very quick and fair peer-review system, which is all easy to use. Visit http://www.dovepress.com/testimonials.php to read real quotes from published authors. 